Non-Western perspectives emphasizing community, lifelong learning, and holistic conceptions of learning are expanding our understanding of adult learning.

\title{
Non-Western Perspectives on Learning and Knowing
}

\author{
Sharan B. Merriam, Young Sek Kim
}

\begin{abstract}
The elder's opinion is truth. All power, all truth comes up from the roots of the family tree, the dead ancestors, to the trunk, the elders, and passes up to parents and children, the branches, leaves and flowers.
\end{abstract}

—Hamminga, 2005, p. 61

As the image conveys, what counts as knowledge and truth in an African context is deeply embedded in the community and is a product of age and experience. This view is in contrast to "the western strategy of convincing with arguments. From the African point of view, arguments are a sign of weakness, of lack of power and vitality. A good, forceful truth does not need arguments. . . Truth is not argued for but felt . . a as a force coming from the speaking human" (Hamminga, 2005, p. 61; emphasis in original).

This is but one example of how another epistemological system or worldview differs from what we in Western society are accustomed to in our understanding of adult learning. The purpose of this chapter is to introduce readers to systems of learning and knowing different from our Western perspective. Many of these systems predate Western science by thousands of years, and even today they are held by the majority of the world's peoples. We first discuss the growing awareness of non-Western perspectives. This discussion is followed by three themes characterizing adult learning in nonWestern systems. We close with a discussion of how familiarity with these perspectives can extend our understanding and practice as adult educators and learners.

\section{कWILEY}

\section{InterScience ${ }^{*}$}

New Directions for Adult And Continuing Education, no. 119, Fall 2008 @ 2008 Wiley Periodicals, Inc. 


\section{Globalization and the Non-Western World}

While we were writing this chapter, the U.S. economy teetered on the brink of a recession. Stock markets in Asia, Europe, and Latin America fell and rose in sync with U.S. swings and adjustments. There can be no doubt that what happens in one part of the world today affects the rest of the world. We are in an era of globalization, of being interconnected economically, culturally, technologically, and educationally with the rest of the world. Through the global economy, technology, travel, and immigration and migration, we come into contact with people from all over the world.

This awareness of our interconnectedness has also been sharpened by our concern with how humans are affecting the health of the planet itself. As O'Sullivan (1999) points out, our science and technology has afforded us "extraordinary control. . . . We command nuclear energy. We travel into space. We know the genetic coding process. We are also in the process of destroying the carrying capacity of the earth for our species as well as the larger biotic world" (p. 180). Indeed, "it would be difficult to find an educational system in the world that was not in the midst of a navigational solution in the turbulent waters of change that globalization has brought about" (Hilgendorf, 2003, p. 72).

Many writers advocate more of a global if not a cosmic consciousness, and we can learn what this is from non-Western systems of thought. Historically, however, "we have labeled cultures as retrograde for having a larger cosmology embedded in mythic structures" and in so doing have "established western scientific thinking as superior to the thinking of other existing cultures" (O'Sullivan, 1999, p. 181). So-called Western knowledge is a relatively recent phenomenon, first spread through colonization and then through globalization. Anchored in classical Greek thought, the dominance of Western knowledge has resulted in nonattention to, if not outright dismissal of, other systems, cosmologies, and understandings about learning and knowing. Only recently have we witnessed a growing interest in learning as an embodied, spiritual, or narrative phenomenon (see the chapters in this volume), or as something structured by a wholly different worldview (Johansen and McLean, 2006; Merriam, 2007).

The terms Western and non-Western are of course problematic, beginning with the fact that setting up dichotomies in the first place is a very Western activity. Further, many indigenous peoples live in Western countries. Imperfect as it is, our use of non-Western might be thought of as a shorthand reference to systems of thought different from what we in the West have come to assume about the knowledge base of adult learning theory.

Encompassed within our use of the term non-Western are what are known as "indigenous" knowledge systems. Dei, Hall, and Rosenberg (2000) identify these characteristics as common to many indigenous cultures: "Seeing the individual as part of nature; respecting and reviving the wisdom of elders; giving consideration to the living, the dead, and future 
generations; sharing responsibility, wealth, and resources within the community; and embracing spiritual values, traditions, and practices reflecting connections to a higher order, to the culture, and to the earth" (p. 6). Our discussion of non-Western perspectives of learning and knowing thus includes indigenous knowledge systems and major philosophical and religious systems of thought. Of course, how we categorize these systems is less important than recognizing that non-Western worldviews do have something to tell us about learning and knowing.

\title{
Learning and Knowing from Non-Western Worldviews
}

A number of writers have compared Western and non-Western or indigenous knowledge systems. Burkhart (2004) points out that knowledge in a Western paradigm is defined by propositional statements, that is, "that something is so'" (p. 19). Propositional knowledge is usually written, considered true, separate from the self, and permanent. Indigenous knowledge is that which we know in experience; it is "the kind of knowledge we carry with us." It is "embodied knowledge" (p. 20).

The notion that knowledge itself is fundamentally different in Western and non-Western systems leads to a difference in how knowledge is constructed, how people "learn" and the best way to instruct, that is, enable people to learn what they need to know. From reading widely, and indeed from experiencing different systems ourselves, we have selected three themes for attention: learning is communal, learning is lifelong and informal, and learning is holistic.

Learning Is Communal. In 2006, author Melissa Fay Greene published the true story of Haregewoin Teferra, an Ethiopian woman who dealt with the death of her husband and daughter by providing a refuge for children of AIDS-stricken families. Greene titled the book after an African proverb, There Is No Me Without You. Indeed, not only is learning a communal activity in many non-Western countries, so too is construction of one's identity. This same idea is echoed in Native American thought: "We are, therefore I am." Burkhart (2004) explains:

\begin{abstract}
In Western thought we might say that my experiences and thoughts count more than your experiences because I have them and you cannot. But if we are WE, then this constraint seems rather trivial. The hand may not have the same experiences as the foot, but this hardly matters if we understand them not as feet and hands but as this body. If it is through the body, or the people, that understanding arises, then no one part need shape this understanding [p. 26].
\end{abstract}

From this communal perspective, learning is the responsibility of all members of the community because it is through this learning that the community itself can develop. 
This notion of community and interdependence plays out in a Buddhist worldview as a form of systems theory wherein in a work setting it is important "to look at the interrelationships between ourselves, our clients, and other members of the organization. Buddhism recognizes that nothing exists in isolation; everything and everyone is the product of the interactions between other things and people" (Johansen and Gopalakrishna, 2006, p. 343).

The Hindu worldview extends this notion of community even further. In writing about the Hindu perspective on learning in the workplace, Ashok and Thimmappa (2006) point out that "individuals, organizations, society, the universe, and the cosmos are all interrelated and integrated. The development of human resources is thus viewed in terms of facilitating the individual to realize oneself and to understand the intricate relationship between the individual and his or her role in the organization, the role of the organization in the society, society in the universe, and the universe within the cosmos" (p. 329).

The individual then, does not learn for his or her own development, but for what can be contributed to the whole. In some cultures, our Western notion of personal independence and empowerment is considered immature, self-centered, and detrimental to the group (Nah, 1999). So intertwined is the individual with the community that isolation or expulsion from some communities is considered to be "worse than dying" (Hamminga, 2005, p. 59).

Related to this communal and interdependent understanding of learning is the view that one's learning must benefit the community. Human resource development (HRD) in many non-Western countries serves to develop individual employees and the corporation but is as well considered instrumental in "nation building." Today in China, national policy is promoting a learning society to address social issues that have emerged from China's exploding market economy. The goal of this lifelong learning society is the very Confucian ideal of creating a harmonious society.

In addition to learning itself being embedded in the community and for the enhancement of the community rather than the individual, in some non-Western systems one has an obligation to share what has been learned. In Islam, for example, "if there is no medical doctor to serve a community, then it is obligatory upon the community to send one or more of its members for medical training, and failure to do so will result in each member sharing the community sin" (Kamis and Muhammad, 2007, p. 28). There is an obligation to share what is learned; in many non-Western communities it is the responsibility of members to both teach and learn. In commenting on several non-Western traditions presented in his book, Reagan (2005) observed that the notion of some adults being teachers with "specialized knowledge and expertise not held by others" (p. 249) was an "alien" concept.

Learning Is Lifelong and Informal. Whispered into the ear of a newborn Muslim infant is the Muslim call to prayer; they are also the last words whispered to a dying family member. So is characterized the Muslim's 
lifelong journey of learning. "Muslims believe that God's knowledge is infinitely vast . . . like a drop of water in the sea; one can never complete acquiring it" (Kamis and Muhammad, 2007, pp. 34-35). This belief translates into Muslims' emphasis on learning both sacred and secular knowledge throughout their lives.

It is important to note that even though some Western scholars do promote a seamless vision of lifelong learning, one that spans the whole of a person's life, it is more commonly thought of as something for adults to engage in. Boshier (2005) has observed that in general, in the West "lifelong learning is nested in an ideology of vocationalism. Learning is for acquiring skills enabling the learner to work harder, faster and smarter and to help their employer compete in the global economy. . . . It is nested in a notion of the autonomous free-floating individual learner as consumer and mostly abdicates responsibility for the public good" (p. 375).

This more formal, market-driven version of lifelong learning is quite different from what non-Western traditions refer to when speaking of learning as lifelong. For example, from a Buddhist worldview one is consciously mindful, attending to everything in daily life throughout life, and the learning that accrues from this mindfulness is its own reward. The motivation to learn "does not rest on getting anything in particular or on being competitive with others. . . Motivation comes out of a noble, altruistic goal for the learning, rather than a less inclusive and more selfish one of an economic or competitive nature" (Johnson, 2002, p. 110). Indeed, this mindfulness is a journey that extends through "innumerous" lives (Shih, 2007, p. 109). Likewise, Hindus see themselves on a continuous journey of learning that leads to being liberated from the cycle of rebirth and death (Thaker, 2007). Yet another perspective, Confucianism, views learning as a never-ending process toward becoming fully human (Kee, 2007).

Lifelong learning and its connection to the communal, interdependent nature of learning is particularly visible in non-Western indigenous cultures. Avoseh (2001) speaks to the interaction between being an active citizen in the community and lifelong education in traditional African society. Education "was a lifelong process that could not be separated from the rest of life's activities. Its purpose was to empower the individual to be an active member of the community" (p. 482). Indeed, lifelong learning is so embedded in the community "that anyone who fails to learn, among the Yorubas for instance, is regarded as oku eniyan (the living dead)" (p. 483).

What is also clear about non-Western understandings of lifelong learning is that very little of it is lodged in formal institutional settings. Lifelong learning in non-Western settings is community-based and informal. Though certainly the majority of lifelong learning is informal even in the West, the difference is that most Westerners neither recognize nor value learning that is embedded in everyday life. Most Westerners think of learning as that which occurs in a formal teacher-directed classroom with a prescribed curriculum. 
By contrast, lifelong learning in non-Western societies is structured by a community problem or issue. Resources in the form of people and materials are brought together to assess the problem and try out solutions. Such learning is "evaluated" by how effective the strategy is in addressing the problem. Fasokun, Katahoire, and Oduaran (2005) write about the informal nature of lifelong learning in Africa: informal learning "involves learning through experience under enabling conditions that facilitate the development of knowledge, skills, attitudes, aptitudes, values and interests. This is done to enhance performance, bring about change or solve practical problems" (p. 36).

The prevalence of informal learning is not to say that formal (often Western) education is not valued at all. Globalization especially has stimulated more demand for formal educational training throughout the world. However, although the West tends to conflate learning with education and formal schooling ("a tendency reflected in our concern with formal certification and degrees rather than with competence per se"), such a perspective is "far less common in non-Western traditions" (Reagan, 2005, p. 248).

Learning Is Holistic. "I think, therefore I am." Descartes's famous maxim captures the West's emphasis on learning as a cognitive process, one that takes place in the brain. Since the seventeenth century, the mind has been privileged as the site of learning and knowing. Even more recent understandings of knowing posit construction of knowledge as a process of mentally reflecting on experience. Only recently have we in adult education given serious attention to somatic knowing, that is, learning through the body, and the place of one's spirit in learning (see chapters in this volume).

If there's anything that non-Western systems of learning and knowing have in common, it's the notion that learning involves not only the mind but the body, the spirit, and the emotions. There is no separation of the mind from the rest of our being. In a discussion of the place of spirituality in Maori curriculum, for example, Fraser (2004) recounts how their holistic perspective is pictured by the Maori as their traditional meeting house. "The four walls of the house are a metaphor for the dimensions of each person. In this model, well-being (or hauora) comprises four components: the physical, the mental and emotional (taken as one), the social and the spiritual. . . A All four dimensions are necessary for strength and symmetry and ... there are reciprocal influences between each one" (p. 89). Like the Maori, Native Americans see all life as interconnected, as in a circle where "everything . . . is connected to everything," and "learning must proceed in a cumulative and connected manner" (Allen, 2007, p. 51).

In non-Western traditions, learning and education are in the service of developing more than just the mind. Equally important is developing a moral person, a good person, a spiritual person, who by being part of the community uplifts the whole. In the Navajo tradition, "knowledge, learning, 
and life itself are sacred, inseparable, and interwoven parts of a whole. The quality of each determines the quality of the other" (Benally, 1997, p. 84; italics in original). In contrast, the West "separates secular and sacred knowledge and thus fragments knowledge. Consequently, some learning is forgotten soon after academic program requirements are met because it was never grounded or connected to life processes" (p. 84). Because indigenous peoples do not separate the sacred from the secular, it is not at all "personally or communally troubling" that human experiences, "especially 'religious' experiences, are not reducible to objects or logic" (Wildcat, 2001, p. 53).

Unlike the West, which privileges abstract and theoretical knowledge, non-Western traditions privilege experience in the everyday world. Learning that occurs in the experience is holistic; it has not just cognitive but physical, emotional, and sometimes spiritual dimensions, all of which are kept in balance. The Hindu tradition of Yoga, for example, employs the mind, body, and spirit in concert to work toward enlightenment. Buddhists seek a "middle way," or balance between body and mind in pursuing enlightenment. Native Americans use the medicine wheel to capture the idea of balancing the four components of a whole person (spiritual, emotional, physical, and mental): "When each aspect is developed equally, an individual is considered well-balanced and in harmony" (Hart, 1996, p. 66). The treatment of disease (dis-ease) assumes that the person is out of balance. Such notions of balance and harmony "extend to others, the family, the community, the natural and spirit worlds, to all that is living" (p. 67).

Given that learning is embedded in the context of everyday experience, active participation in everyday activities and the rites and rituals of a community are seen as conduits to learning. Learning occurs through observation of others and through practicing what is being learned. Adults are role models for younger people. In Buddhist, Hindu, Islamic, and Confucian traditions, the learner is expected to emulate teachers, sages, or more accomplished practitioners of the tradition.

Many other sources are readily recognized as mechanisms for learning in non-Western traditions. Stories, myths, and folklore define one group from another and one's place in the larger society. Rituals, symbols, music, art, theater, and even dreams and visions are also considered sources of knowledge. Ntseane (2007) notes that it is common practice in Botswana for traditional healers to rely on dreams in which spirits of the ancestors "instruct the healer on how to heal the patient and with what herbs" (p. 127).

The holistic nature of learning in non-Western traditions is of course interrelated with learning being a lifelong journey, a journey in community with others. At some level, most adult educators recognize that learning can be more than formal schooling, and knowledge can be more than abstract cognition. We turn now to how becoming acquainted with non-Western perspectives can enhance our practice. 


\section{Non-Western Perspectives and Our Practice of Adult Learning}

Our exposure to non-Western perspectives of learning and knowing can influence our practice as adult educators in three ways: approaching learning holistically, valuing learning embedded in everyday life, and being responsive to learners from other cultures.

First, non-Western perspectives of learning and knowing model a holistic approach to learning, one that recognizes the interrelationship among an adult learner's body, cognition, emotion, and spirituality. Sina, a Muslim philosopher and physician in the eleventh century, for example, believed that body and emotions are closely connected; therefore a student's body can benefit when educators help students have positive emotions (Gunther, 2006). In the American Indian perspective, emotion is the foundation where we can develop a relationship between what we are learning and why we are learning it; love for people and one's land has been a primary reason for learning (Cajete, 2005). When Fraser (2004) reviewed adult learning from the perspective of the Maori, who value spirituality, she suggested that adult educators need to encourage adult learners to reflect on the meaning and purpose of life. Because the adult learner's body, cognition, emotion, and spirituality are closely interrelated, in Western society adult learners are likely to have more meaningful learning experiences if these interconnections are attended to.

Second, familiarity with non-Western perspectives of learning and knowing suggests that adult educators in Western society might place more value on learning embedded in everyday life. Because non-Westerners believe that knowledge is embedded in experiences in everyday life, they do not value what is learned in formal school settings more than what is learned in daily life. Indigenous knowledge is about what people learn in experience and deals with real problems and issues in community. Rather than emphasizing prefixed curriculum-driven learning, formal certification, and degrees, we in the West might make more visible the nonformal and informal learning that even here characterizes the majority of adult learning.

In American Indian society, for example, there is no general knowledge; each individual constructs his or her own knowledge "through patient observation and contemplation and not by question-formulation and hypothesis-testing" (Burkhart, 2004, p. 23). In addition, in Latin America, influenced by liberation theology, the grassroots community organization offers nonformal and informal learning opportunities for the poor where knowledge is transmitted in one-to-one small groups or through performance (Conceiçã and Oliveria, 2007). Western societies, which assume knowledge exists in the form of abstraction, often neglect how each individual's construction of specific knowledge in real life is valuable and how adults can teach and learn from each other to solve real-life problems 
outside the classroom. In practice, adult learners can be more encouraged to build their own knowledge, which can be put to use not by hypothesis testing or question formulation in the classroom but by observing and contemplating their unique experiences in real life.

Third, being familiar with non-Western perspectives of learning and knowing helps adult educators better understand how adult learners from non-Western societies act and think. With advances of technology and transportation, adult educators in Western societies are coming into contact with students who have other than Western worldviews. Many Asian learners, for example, adhere to a Confucian worldview that positions learning within the hierarchical structures of human relationships; such structures are designed to achieve a harmonious social order (Kee, 2007). Teachers thus have authority and power over students in this hierarchy. Confucianism assumes that students need to receive knowledge from teachers, without critique, and then memorize it. In Confucianism, criticizing a teacher's opinion or having opinions different from those of classical works was seen as breaking the harmonious social order; therefore, students from Confucian cultures need more guidance to think critically or engage in creative expression, both of which are valued in Western society (Yang, Zheng, and Li, 2006).

In collectivist cultures in Africa, an individual needs to take responsibility for others; individual interests are always less important than communal interests (Ntseane, 2006). For example, HIV/AIDS prevention strategies that emphasize a community problem (an ethical concern with the suffering of others) are more effective than strategies focusing on an individual health problem (the fear of death; Ntseane, 2006). Therefore, adult education practices that aim for self-actualization or personal growth would not resonate well with students from African or other collectivist cultures.

\section{Conclusion}

Our exposure to non-Western perspectives on learning and knowing broadens our understanding of adult learning and enhances our practice as educators in a global society. We hope that this chapter is just a starting point, encouraging you to look around and notice more diverse ways of learning and knowing. A more inclusive practice can enrich our lives and the lives of learners with whom we work.

\section{References}

Allen, P. G. "American Indian Indigenous Pedagogy." In S. B. Merriam (ed.), Non-Western Perspectives on Learning and Knowing (pp. 41-56). Malabar, Fla.: Krieger, 2007. 
Ashok, H. S., and Thimmappa, M. S. "A Hindu Worldview of Adult Learning in the Workplace." Advances in Developing Human Resources, 2006, 8(3), 329-336.

Avoseh, M.B.M. "Learning to Be Active Citizens: Lessons of Traditional Africa for Lifelong Learning." International Journal of Lifelong Education, 2001, 20(6), 479-486.

Benally, H. J. "The Pollen Path: The Navajo Way of Knowing." In R. P. Foehr and S. A. Schiller (eds.), The Spiritual Side of Writing (pp. 84-94). Portsmouth, N.H.: Boynton/Cook, 1997.

Boshier, R. "Lifelong Learning." In L. M. English (ed.), International Encyclopedia of Adult Education (pp. 373-378). New York: Palgrave Macmillan, 2005.

Burkhart, B. Y. "What Coyote and Thales Can Teach Us: An Outline of American Indian Epistemology." In A. Waters (ed.), American Indian Thought (pp.15-26). Victoria, Aus.: Blackwell, 2004.

Cajete, G. "American Indian Epistemologies." In M.J.T. Fox, S. C. Lowe, and G. S. McClellan (eds.), Serving Native American Students (pp. 69-78). San Francisco: JosseyBass, 2005.

Conceiçã, S.C.O., and Oliveria, A.M.F. "Liberation Theology and Learning in Latin America." In S. B. Merriam (ed.), Non-Western Perspectives on Learning and Knowing (pp. 41-56). Malabar, Fla.: Krieger, 2007.

Dei, G. J., Hall, B. L., and Rosenberg, D. G. "Introduction." In G. J. Dei, B. L. Hall, and D. G. Rosenberg (eds.), Indigenous Knowledges in Global Contexts (pp. 3-17). Toronto: University of Toronto Press, 2000.

Fasokun, T., Katahoire, A., and Oduaran, A. The Psychology of Adult Learning in Africa. Hamburg, Germany: UNESCO Institute for Education and Pearson Education, South Africa, 2005.

Fraser, D. "Secular Schools, Spirituality and Maori Values." Journal of Moral Education, 2004, 33(1), 87-95.

Greene, M. F. There Is No Me Without You: One Woman's Odyssey to Rescue Africa's Children. New York: Bloomsbury, 2006.

Gunther, S. "Be Masters in That You Teach and Continue to Learn: Medieval Muslim Thinkers on Educational Theory." Comparative Education Review, 2006, 50(3), 367-388.

Hamminga, B. "Epistemology from the African Point of View." In B. Hamminga (ed.), Knowledge Cultures: Comparative Western and African Epistemology (pp. 57-84). Amsterdam and New York: Rodopi, 2005.

Hart, M. A. "Sharing Circles: Utilizing Traditional Practice Methods for Teaching, Helping, and Supporting." In S. O'Meara and D. A. West (eds.), From Our Eyes: Learning from Indigenous Peoples (pp. 59-72). Toronto, Ont.: Garamond Press, 1996.

Hilgendorf, E. "Islamic Education: History and Tendency." Peabody Journal of Education, 2003, 78(2), 63-75.

Johansen, B-C. P., and Gopalakrishna, D. "A Buddhist View of Adult Learning in the Workplace." Advances in Developing Human Resources, 2006, 8(3), 337-345.

Johansen, B.-C. P., and McLean, G. W. "Worldviews of Adult Learning in the Workplace: A Core Concept in Human Resource Development." Advances in Developing Human Resources, 2006, 8(3), 321-328.

Johnson, I. "The Application of Buddhist Principles to Lifelong Learning." International Journal of Lifelong Education, 2002, 21(2), 99-114.

Kamis, M., and Muhammad, M. "Islam's Lifelong Learning Mandate." In S. B. Merriam (ed.), Non-Western Perspectives on Learning and Knowing (pp. 21-40). Malabar, Fla.: Krieger, 2007.

Kee, Y. "Adult Learning from a Confucian Way of Thinking." In S. B. Merriam (ed.), Non-Western Perspectives on Learning and Knowing (pp. 153-172). Malabar, Fla.: Krieger, 2007. 
Merriam, S. B. (ed.). Non-Western Perspectives on Learning and Knowing. Malabar, Fla.: Krieger, 2007.

Nah, Y. "Can a Self-Directed Learner Be Independent, Autonomous and Interdependent?: Implications for Practice." Adult Learning, 1999, 11, 18-19, 25.

Ntseane, G. "Western and Indigenous African Knowledge Systems Affecting Gender and HIV/AIDS Prevention in Botswana." In S. B. Merriam, B. C. Courtenay, and R. M. Cervero (eds.), Global Issues and Adult Education: Perspectives from Latin America, Southern Africa, and the United States (pp. 219-230). San Francisco: JosseyBass, 2006.

Ntseane, G. "African Indigenous Knowledge: The Case of Botswana." In S. B. Merriam (ed.), Non-Western Perspectives on Learning and Knowing (pp. 113-136). Malabar, Fla.: Krieger, 2007.

O'Sullivan, E. Transformative Learning. Toronto: University of Toronto Press, 1999.

Reagan, T. Non-Western Educational Traditions: Indigenous Approaches to Educational Thought and Practice (3rd ed.). Hillsdale, N.J.: Erlbaum, 2005.

Shih, J. "Buddhist Learning: A Process to Be Enlightened." In S. B. Merriam (ed.), NonWestern Perspectives on Learning and Knowing (pp. 99-112). Malabar, Fla.: Krieger, 2007.

Thaker, S. N. "Hinduism and Learning." In S. B. Merriam (ed.), Non-Western Perspectives on Learning and Knowing (pp. 57-74). Malabar, Fla.: Krieger, 2007.

Wildcat, D. R. "The Schizophrenic Nature of Metaphysics." In V. Deloria, Jr., and D. Wildcat, Power and Place: Indian Education in America (pp. 47-55). Golden, Colo.: American Indian Graduate Center and Fulcrum Resources, 2001.

Yang, B., Zheng, W., and Li, M. "Confucian View of Learning and Implications for Developing Human Resources." Advances in Developing Human Resources, 2006, 8(3), 346-354.

SHARAN B. MERRIAM is professor of adult education at the University of Georgia, Athens.

YOUNG SEK KIM is a Ph.D. graduate in adult education from the University of Georgia. 
Copyright of New Directions for Adult \& Continuing Education is the property of John Wiley \& Sons, Inc. / Education and its content may not be copied or emailed to multiple sites or posted to a listserv without the copyright holder's express written permission. However, users may print. download, or email articles for individual use. 